\title{
Plasma concentrations of progesterone and 13,14- dihydro-15-keto-prostaglandin $F-2 \alpha$ during regression of the corpora lutea of lactation in the bandicoot (Isoodon macrourus)
}

\author{
R. T. Gemmell \\ Department of Anatomy, University of Queensland, St Lucia, Queensland 4067, Australia
}

\begin{abstract}
Summary. Plasma progesterone concentrations (mean \pm s.e.m.) declined from $7.5 \pm$ $1.2 \mathrm{ng} / \mathrm{ml}$ and $7.5 \pm 1.0 \mathrm{ng} / \mathrm{ml}$ to $<1 \mathrm{ng} / \mathrm{ml}$ after removal of pouch young (RPY) from bandicoots at Days 24 and 30 of lactation respectively. In all 7 bandicoots, the corpora lutea of lactation showed signs of regression and, in 5 of these bandicoots, a premature ovulation had occurred 6-9 days after RPY. There was no change in the concentration of PGFM after RPY, and uterine prostaglandin F-2 $\alpha$ may not be involved in luteal regression in the bandicoot.
\end{abstract}

\section{Introduction}

The bandicoot, Isoodon macrourus, is a small terrestrial marsupial with a gestation period of $12 \cdot 5$ days (Lyne, 1974) which is shorter than the oestrous cycle length of 20 days (Lyne, 1976). A litter size of 4 is observed at birth (Gemmell, 1982) and the young are suckled for about 59 days. Unlike most marsupials, in the bandicoot the corpora lutea of pregnancy persist for about 42 days of lactation (Hughes, 1962; Gemmell, 1979). If the pouch young are removed after Day 20 of lactation, regression of the corpora lutea occurs and a new ovulation takes place 5-10 days later (Hughes, 1962; Close, 1977; Gemmell, 1981). In some species, such as the sheep and the guineapig, the uterine prostaglandins are the most important single factor that determine the regression of the corpus luteum (Rothchild, 1981). However, in a great many other species, for example, the rabbit, rat, primates, and monoestrous breeders such as the cat, the uterus does not affect luteal regression. Hysterectomy does not affect the ovarian cycle of the Virginian opossum, Didelphis virginiana (Hartman, 1925), and brush possum, Trichosurus vulpecula (Clark \& Sharman, 1965). Rothchild (1981) therefore suggested that intraluteal prostaglandins are the final common agent of luteolysis in all mammals, and that they have remained the sole source of luteolytic prostaglandins in some mammals, whilst prostaglandins from the uterus have supplemented their production in other species.

In the present study, the role of prostaglandin in the regression of the bandicoot corpora lutea was investigated.

\section{Materials and Methods}

\section{Animals}

Blood samples were obtained every 2 nd day from 3 adult female bandicoots (I. macrourus), with 3 young each (Nos 1-3) and from another 3 bandicoots each with 1 young (Nos 4-6) from Days 22 to 44 of lactation. Daily blood sampling increases the probability of loss of pouch young. Blood 
samples were also obtained daily from $4(\operatorname{Nos} 7-10)$ and $3($ Nos 11-13) adult female bandicoots after removal of pouch young on Day 24 and Day 30 of lactation, respectively. The day of lactation was determined by observing the day of birth or by estimating the age of the pouch young from the length of the head and the total body weight according to the method described for the long-nosed bandicoot, Perameles nasuta, by Lyne (1964). Blood samples were obtained by heart puncture from animals which had been lightly anaesthetized with a halothane (Fluothane: ICI) and oxygen mixture. Samples were taken daily up to 3 days before and for about 10 days after removal of pouch young. The ovaries of each bandicoot were examined 9-13 days after pouch young removal. Laparotomies were carried out according to the procedure outlined by Gemmell (1979).

Assays

Progesterone. Plasma progesterone concentrations were determined by the radioimmunoassay described previously (Gemmell, 1979) using sheep anti-progesterone-11-hemisuccinate-BSA kindly donated by Dr R. I. Cox. The antiserum is highly specific for progesterone, the only significant cross-reaction being that with $11 \beta$-hydroxyprogesterone $(11.9 \%)$. The limit of the sensitivity of the assay was $25 \mathrm{pg} /$ tube and the inter-assay coefficient of variation was $14.0 \%(n=$ 10). All samples from each animal were completed in the same assay. The assay buffer blank was $<0.1 \mathrm{ng} / \mathrm{ml}$ and the efficiency of extraction of progesterone from plasma was $87.0 \%$ $(n=10)$.

PGFM. Concentrations of 13,14-dihydro-15-keto-prostaglandin F-2 $\alpha$ (PGFM) were determined in plasma samples by a modification of the method of Mitchell, Flint \& Turnbull (1976) as described previously (Gemmell, Jenkin \& Thorburn, 1980). The limit of sensitivity of the assay was $10 \mathrm{pg} /$ tube. Again all samples from each animal were completed in the same assay. The inter-assay coefficient of variation was $17.5 \%$, assay buffer blank was $0.13 \mathrm{ng}(n=39)$, the non-specific binding was $1 \cdot 5 \%(n=27)$ and the efficiency of extraction of $\left[{ }^{3} \mathrm{H}\right] \mathrm{PGFM}$ from plasma was $87.6 \%(n$ = 39).

\section{Results}

The plasma progesterone concentration was greater in the 3 bandicoots (Nos 1-3) suckling 3 young than in the 3 bandicoots (Nos 4-6) suckling 1 young (Text-fig. 1): the mean \pm s.e.m. $(n=12)$ plasma progesterone from Day 22 to 44 of lactation was $13.06 \pm 1 \cdot 34,4 \cdot 53 \pm 0 \cdot 76$ and $8 \cdot 11 \pm 0 \cdot 73$ $\mathrm{ng} / \mathrm{ml}$ in Bandicoots 1, 2 and 3 and $3.29 \pm 0.24,2.91 \pm 0.29$ and $3.06 \pm 0.31 \mathrm{ng} / \mathrm{ml}$ in Bandicoots 4, 5 and 6.

After removal of the pouch young from Bandicoots 7-13, plasma progesterone concentrations (mean \pm s.e.m.) decreased in each animal, being $7.5 \pm 1.2 \mathrm{ng} / \mathrm{ml}(n=10)$ on Days $22-24$ and $7.5 \pm$ $1.0 \mathrm{ng} / \mathrm{ml}(n=7)$ on Days 28-30 before and $<1 \mathrm{ng} / \mathrm{ml}$ by $2-7$ days after removal of pouch young (Text-fig. 2).

The plasma progesterone concentration in Bandicoots 8, 9, 10, 11 and 13 increased about 10 days after removal of pouch young to reach values comparable to those observed during an oestrous cycle (Text-fig. 2). Large, pink, highly vascularized corpora lutea about $2 \mathrm{~mm}$ in diameter were observed adjacent to the pale regressing corpora lutea $<1 \mathrm{~mm}$ in diameter in 5 bandicoots (Table 1). This macroscopic observation was confirmed by histological examination of the ovaries of Bandicoot 11: actively secreting corpora lutea, $2 \mathrm{~mm}$ in diameter, were observed beside corpora albicantia of the previous pregnancy and lactation.

In Bandicoots 7 and 12, the plasma progesterone concentration did not increase above $6 \mathrm{ng} / \mathrm{ml}$ after the fall following pouch young removal, and the corpora lutea which were examined 6,13 (Bandicoot 7) and 9 (Bandicoot 12) days after removal of pouch young were small in size and did not have the pink colour of richly vascularized tissue seen in recently formed corpora lutea (Table 1). 


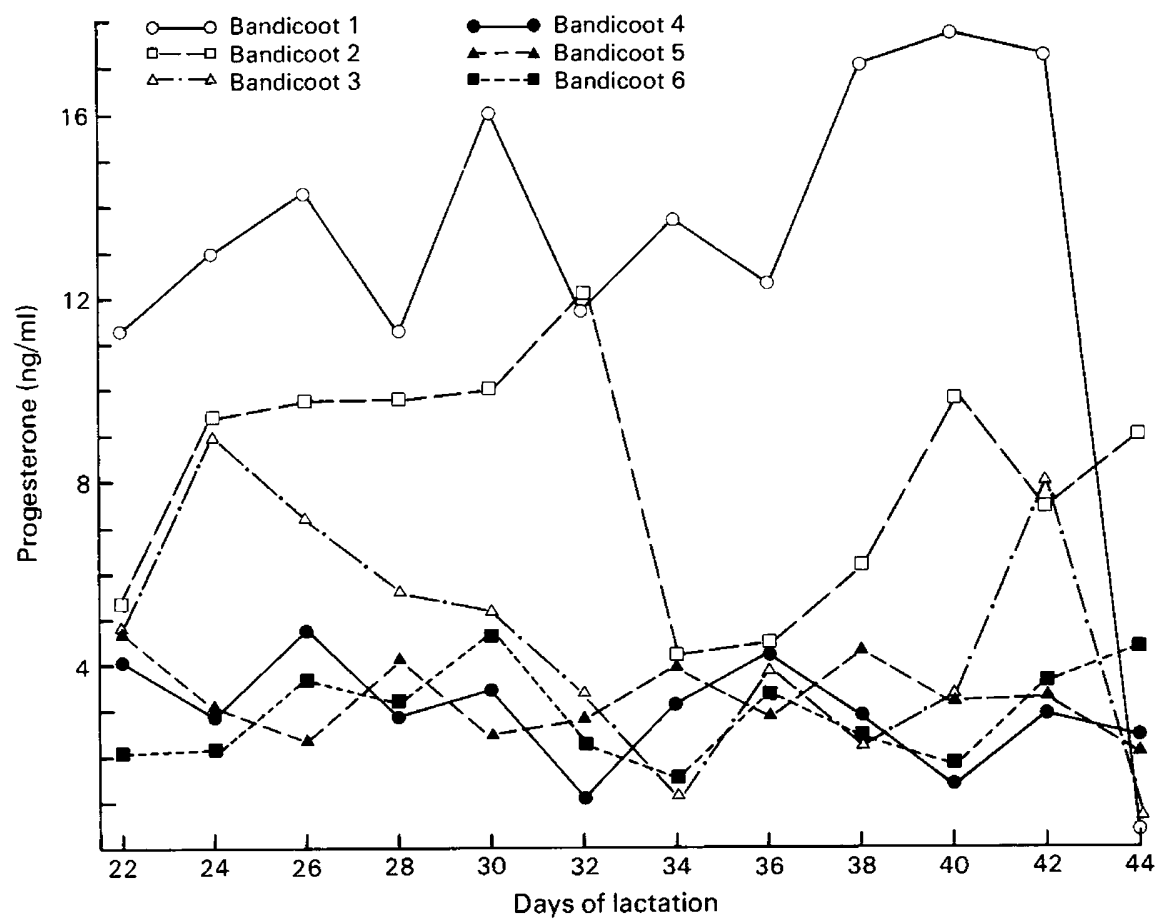

Text-fig. 1. The plasma progesterone concentrations of Bandicoots 1,2 and 3 suckling 3 young each and Bandicoots 4, 5 and 6 with 1 young each.

The concentration of PGFM did not alter in any of Bandicoots 7-13 after removal of pouch young. In 5 animals in which a new ovulation occurred, the mean \pm s.e.m. concentration of plasma PGFM was $0.35 \pm 0.06 \mathrm{ng} / \mathrm{ml}(n=15)$ during the 3 days before and $0.34 \pm 0.02 \mathrm{ng} / \mathrm{ml}(n=56)$ during the 12 days after removal of pouch young.

\section{Discussion}

When young were removed from the pouch of bandicoots at Days 24 or 30 of lactation, the corpora lutea of the pregnancy and subsequent lactation regressed in all animals and a premature ovulation occurred in 5 bandicoots, 6-9 days later. In all 7 bandicoots, the plasma progesterone values decreased to $0 \cdot 1-0.7 \mathrm{ng} / \mathrm{ml}$ after removal of pouch young.

The plasma progesterone concentration in pregnant and lactating bandicoots has been reported previously to be $12.6 \mathrm{ng} / \mathrm{ml}$ at birth and this level was maintained for at least 4 days into lactation. A gradual decline in plasma progesterone concentration was observed after Day 4 of lactation and basal concentrations were again reached at about Day 19 (Gemmell, 1981). The bandicoot in captivity has a strong tendency to reduce the number in its litter during lactation (Gemmell, 1982). In the study by Gemmell (1981) the hormone values for Days 20-57 were obtained from bandicoots with one young. In this present study, similar plasma progesterone concentrations were obtained from 3 bandicoots each with one sucking young. However, the plasma progesterone concentrations in 3 bandicoots each suckling 3 young were considerably greater during this period of lactation. Further study is required to ascertain whether the number of young present influences the plasma progesterone concentration throughout pregnancy and lactation. 


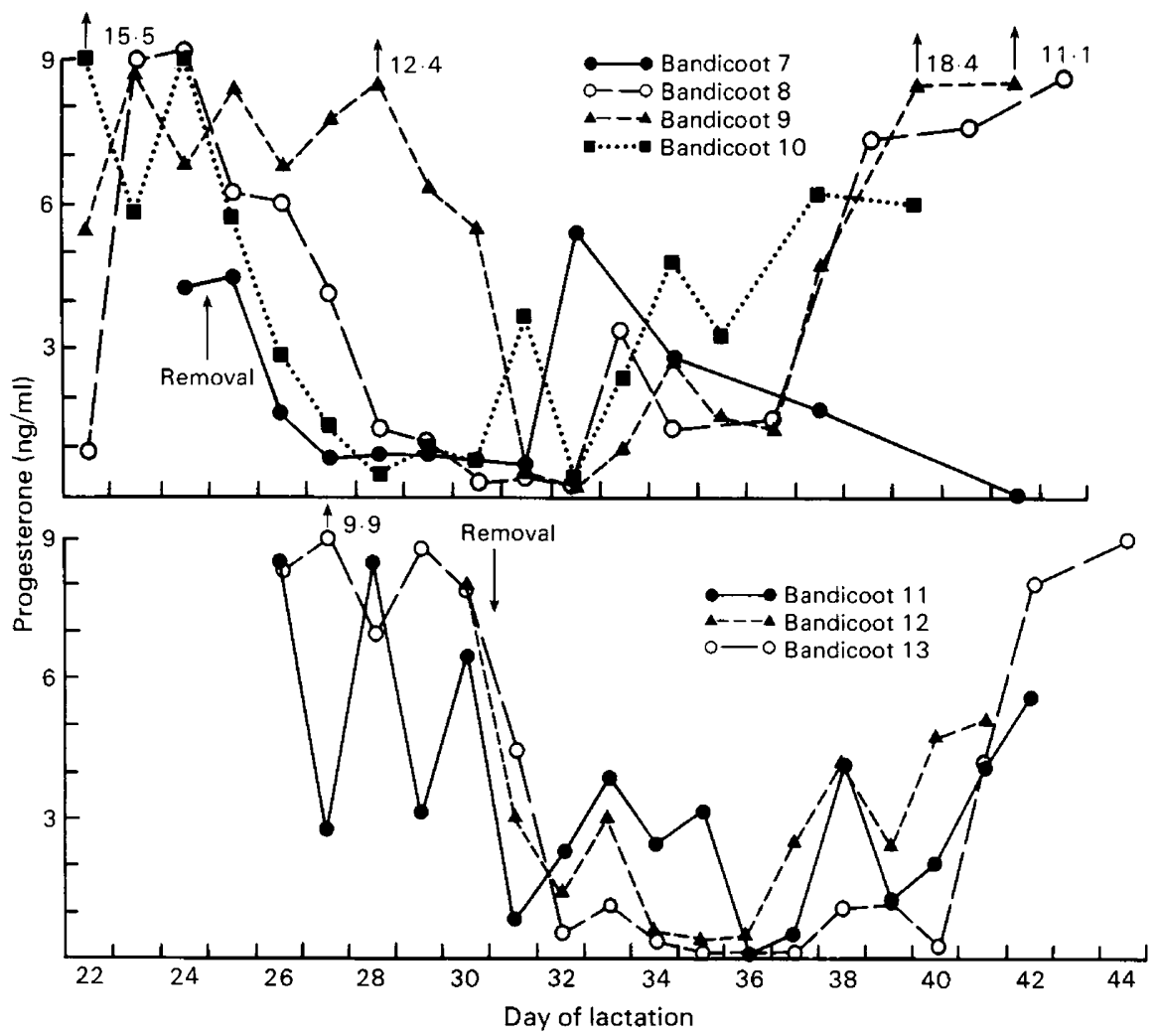

Text-fig. 2. The plasma progesterone concentrations of Bandicoots 7,8, 9 and 10 after removal of pouch young on Day 24 of lactation, and of Bandicoots 11, 12 and 13 after removal of pouch young on Day 30 of lactation.

Table 1. Morphological appearance of bandicoot corpora lutea after removal of pouch young (RPY) at Day 24 or Day 30 of lactation

\begin{tabular}{cccccl}
\hline RPY & Bandicoot & $\begin{array}{c}\text { No. of } \\
\text { young removed }\end{array}$ & $\begin{array}{c}\text { Day of lactation } \\
\text { when examined }\end{array}$ & $\begin{array}{c}\text { Days after } \\
\text { RPY }\end{array}$ & $\begin{array}{c}\text { Appearance of } \\
\text { corpora lutea }\end{array}$ \\
\hline Day 24 & 7 & 2 & 30,37 & 6,13 & CL of lactation \\
& 8 & 3 & 34 & 10 & Recent ovulation \\
& 9 & 3 & 36 & 12 & New CL \\
Day 30 & 10 & 3 & 34 & 10 & New CL \\
& 11 & 4 & 42 & 12 & New CL \\
& 12 & 3 & 39 & 9 & CL of lactation \\
& 13 & 2 & 42 & 12 & New CL \\
\hline
\end{tabular}

The concentration of progesterone in the plasma of entire and castrated males and anoestrous and ovariectomized females is $3-6 \mathrm{ng} / \mathrm{ml}$ (Gemmell, 1979). However, plasma concentrations decreased to below these basal concentrations of $3.0 \mathrm{ng} / \mathrm{ml} \mathrm{immediately} \mathrm{after} \mathrm{excision} \mathrm{of} \mathrm{the} \mathrm{corpus}$ luteum, but recovered to basal concentrations of $3.0 \mathrm{ng} / \mathrm{ml}$ several days later (Gemmell, 1981). It is therefore possible that the adrenal gland has a decreased rate of secretion of progesterone when the corpora lutea are producing progesterone. This would explain the decrease in plasma progesterone 
to $0 \cdot 1-0 \cdot 7 \mathrm{ng} / \mathrm{ml}$ after removal of pouch young, well below the normal basal concentration of $3 \cdot 0$ $\mathrm{ng} / \mathrm{ml}$. With removal of the suckling stimulus, the corpora lutea regress and the plasma progesterone declines to $<1 \mathrm{ng} / \mathrm{ml}$. In Bandicoots 7 and 12, in which a new ovulation did not occur, plasma progesterone concentrations increased to about $3 \mathrm{ng} / \mathrm{ml}$ after reaching a nadir of $<1 \mathrm{ng} / \mathrm{ml}$ several days earlier. From this study it is apparent that the corpora lutea of lactation are producing progesterone on Days 24 and 30 of lactation, especially in bandicoots suckling 3 young. It is therefore probable that the corpora lutea are actively secreting progesterone until Day 42 of lactation, when regression occurs, and the plasma progesterone profile is similar to that of the longlived corpora lutea of the monoestrous eutherian carnivores as suggested by Rothchild (1981).

Despite regression of the corpora lutea after removal of pouch young there was no increase in the plasma concentration of PGFM, suggesting that vascular transport of PGF- $2 \alpha$ is not required for luteal regression. However, it is possible that daily sampling failed to detect the rapid peaks of PGFM known to be associated with luteolysis in some species (Rothchild, 1981). A similar sampling protocol detected large increases of PGFM at birth in the bandicoot (Gemmell et al., 1980 ) but the PGF release patterns may not be similar. It has already been demonstrated that hysterectomy is without significant effect on the oestrous cycle of the opossum, Didelphis virginiana (Hartman, 1925), and the brush possum Trichosurus vulpecula (Clark \& Sharman, 1965). It is therefore unlikely that uterine PGF- $2 \alpha$ plays a role in the regression of the marsupial corpus luteum.

\section{References}

Clark, M.J. \& Sharman, G.B. (1965) Failure of hysterectomy to affect the ovarian cycle of the marsupial Trichosurus culpecula. J. Reprod. Fert. 10, 459-461.

Close, R.L. (1977) Recurrence of breeding after cessation of suckling in the marsupial Perameles nasuta. Aust. J. Zool. 25, 641-645.

Gemmell, R.T. (1979) The fine structure of the luteal cells in relation to the concentration of progesterone in the plasma of the lactating bandicoot, Isoodon macrourus (Marsupialia: Peramelidae). Aust. J. Zool. 27, 501510.

Gemmell, R.T. (1981) The role of the corpus luteum of lactation in the bandicoot Isoodon macrourus (Marsupialia: Peramelidae). Gen. comp. Endocr. 44, 13-19.

Gemmell, R.T. (1982) Breeding bandicoots in Brisbane (Isoodon macrourus; Marsupialia, Peramelidae). Aust. Mammal. 5, 187-193.

Gemmell, R.T., Jenkin, G. \& Thorburn, G.D. (1980) Plasma concentrations of progesterone and 13,14dihydro-15-keto-prostaglandin F-2 $\alpha$ at parturition in the bandicoot, Isoodon macrourus. J. Reprod. Fert. 60. $253-256$.
Hartman, C.G. (1925) Hysterectomy and the oestrous cycle in the opossum. Am. J. Anat. 35, 25-30.

Hughes, R.L. (1962) Role of the corpus luteum in marsupial reproduction. Nature, Lond. 194, 890-891.

Lyne, A.G. (1964) Observations of the breeding and growth of the marsupial Perameles nasuta Geoffroy, with notes on other bandicoots. Aust. J. Zool. 12, $322-339$.

Lyne, A.G. (1974) Gestation period and birth in the marsupial Isoodon macrourus. Aust. J. Zool. 22, 303309.

Lyne, A.G. (1976) Observations on oestrous and the oestrous cycle in the marsupials Isoodon macrourus and Perameles nasuta. Aust. J. Zool. 24, 513-521.

Mitchell, M.D., Flint, A.P.F. \& Turnbull, A.C. (1976) Plasma concentrations of 13,14-dihydro-15-ketoprostaglandin $F$ during pregnancy in the sheep. Prostaglandins 11, 319-329.

Rothchild, I. (1981) The regulation of the mammalian corpus luteum. Recent Prog. Horm. Res. 37, 183-298.

Received 22 November 1983 